\title{
S3 Guideline for Chronic Pancreatitis - Diagnosis, Classification and Therapy for the Radiologist
}

\section{S3-Leitlinie Chronische Pankreatitis: Diagnostik, Klassifikation und Therapie für die Radiologie}

Authors

Affiliations
A. G. Schreyer ${ }^{1}$, M. Jung ${ }^{2}$, J. F. Riemann ${ }^{3}$, C. Niessen ${ }^{1}$, B. Pregler ${ }^{1}$, L. Grenacher ${ }^{4}$, A. Hoffmeister ${ }^{5}$

Department of Radiology, University Hospital Regensburg

Department of Interna! Medicine and Gastroenterology, Catholic Hospital Mainz

Medical Clinic C, Ludwigshafen Hospital

${ }^{4}$ Diagnostic and Interventional Radiology, University Hospital Heidelberg

Medical Clinic and Polyclinic II for Gastroenterology, University Hospital Leipzig
Key words

- pancreas

- CT

- pancreatitis

- MR imaging received 10.2.2014 accepted $\quad 29.6 .2014$

\section{Bibliography}

DOI http://dx.doi.org/

10.1055/s-0034-1385005

Published online: 14.8.2014

Fortschr Röntgenstr 2014; 186:

1002-1008 @ Georg Thieme

Verlag KG Stuttgart · New York . ISSN 1438-9029

\section{Correspondence}

Herr Prof. Andreas G. Schreyer

Institut für Röntgendiagnostik, Universitätsklinikum

Regensburg

Franz-Josef-Strauß-Allee 11

93051 Regensburg

Germany

Tel.: ++ 49/0941/9447401

Fax: ++ 49/09 41/9447402

andreas.schreyer@klinik.uni-

regensburg.de

\section{Abstract \\ $\nabla$}

Chronic pancreatitis shows an increasing prevalence and incidence mainly in the Western Hemisphere. Early diagnosis and therapy are frequently delayed because of non-specific symptoms as well as non-specific blood values. The German Society of Digestive and Metabolic Diseases (DGVS) organized the preparation and publication of an interdisciplinary S3 level guideline with the support of the German Radiological Society (DRG) as 1 of 11 contributing societies. In this article we present and discuss the main topics of the guideline regarding the diagnosis, differential diagnosis and therapy of complications of this complex chronic disease with a focus on clinical and scientific radiologists.

Key Points:

- Ultarsound represents the perfect first line imaging modality

- For further diagnostic werk up MRI with MRCP are recommended for the differentialdiagnosis of pancreatic cancer

- For clinical studies the modified (CT, MRI) Cambridge classification is recommended Citation Format:

- Schreyer AG, Jung M, Riemann JF etal. S3 Guideline for Chronic Pancreatitis - Diagnosis, Classification and Therapy for the Radiologist. Fortschr Röntgenstr 2014; 186: 1002-1008

\section{Zusammenfassung}

Die chronische Pankreatitis hat vor allem in der westlichen Welt in ihrer Inzidenz und Prävalenz stark zugenommen. Durch die unspezifischen Symptome zu Beginn dieser chronischen Erkrankung bei fehlenden spezifischen Laborparametern ist die Diagnose und Therapie häufig verzögert. Über mehrere Jahre wurde die aktuelle neue deutsche S3-Leitlinie „Chronische Pankreatitis“ unter der organisatorischen Leitung der Deutschen Gesellschaft für Verdauung- und Stoffwechselkrankheiten (DGVS) mit Beteiligung der Deutschen Röntgengesellschaft (DRG) als eine von 11 kollaborierenden Gesellschaften interdisziplinär erarbeitet und veröffentlicht. Im vorliegenden Artikel möchten wir alle für den klinisch und wissenschaftlich arbeitenden Radiologen wichtigen Punkte für die Diagnose, Differentialdiagnose sowie Therapie von Komplikationen dieses komplexen chronischen Krankheitsbildes basierend auf der neuen Leitlinie zusammenstellen und diskutieren.

\section{Introduction}

$\nabla$

The prevalence and incidence of chronic pancreatitis are increasing in the Western world. The worldwide incidence is between 1.6 and 23 per 100000 with increasing prevalence [1]. Despite the fact that the disease is typically treated on an outpatient basis, over 10000 inpatient cases per year have been seen in Germany not including the over 50000 cases per year of acute episodes of chronic pancreatitis, which are classified as acute pancreatitis. The overall mortality rate of the disease is specified as approximately $28-35 \%$ with the death rate of the disease being 3.6 times higher compared to the normal population $[2-4]$. Continued alcohol consumption significantly shortens the survival time for the disease. In the case of alcohol abstinence, the 10 -year survival rate is approximately $70 \%$ and the 20 -year survival rate is $45 \%$ [5].

Alcohol is the most important risk factor among adults. However, the relationship to alcohol consumption does not appear to be linear [6]. There is no clear indication that chronic pancreatitis is triggered by cholecystolithiasis or choledocholithiasis [7]. Anato- 
mical variants, such as pancreas divisum, do not appear to be etiological [8].

Despite broad epidemiological distribution and important socioeconomic factors, the diagnosis and treatment of chronic pancreatitis are still delayed and difficult in some cases even in the $21 \mathrm{st}$ century. A problem for early diagnosis is the lack of specific laboratory parameters in the case of frequently non-specific clinical symptoms.

An interdisciplinary evidence-based S3 guideline for the diagnosis, staging, and treatment of chronic pancreatitis was created after many years of preparation and organization by the German Society of Digestive and Metabolic Diseases. Representatives of the Gastrointestinal and Abdominal Diagnostics Workgroup (www.ag-gastro.drg.de) of the German Radiological Society were significantly involved in creating the guideline for imaging diagnostics and treatment.

\section{Method}

\section{$\nabla$}

The guideline recommendations are specified according to the particular level of evidence corresponding to the Oxford scheme (http://www.cebm.net). The recommendations are formulated to reflect the strength of the recommendation. The level of consensus is determined by the percentage agreement of the consensus conference participants as follows: strong consensus $>95 \%$, consensus $65 \%$ to $95 \%$, and majority agreement $50 \%$ to $75 \%$. The guidelines were created according to the regulations of the AWMF for S3 guidelines after the creation of workgroups via systematic and documented literature research and critical evaluation of the literature with consecutive consensus building via Delphi rounds with online questionnaires and a subsequent 2day consensus conference. The following discusses the relevant topics of the guidelines for radiological diagnostics as well as the possible treatment of chronic pancreatitis and its complications. Statements from the guidelines are cited and are then discussed and commented on with a focus on radiological issues regarding diagnostics and treatment.

\section{Definition of chronic pancreatitis}

$\nabla$

Chronic pancreatitis is defined as a disease of the pancreas in which the pancreatic parenchyma is replaced by fibrotic connective tissue as a result of recurring inflammatory episodes. This results in a loss of exocrine and endocrine pancreatic function and typical complications such as pseudocysts, pancreatic duct stenoses, duodenal stenoses, or vascular or biliary tract complications. The main clinical complications and symptoms are malnutrition and pain syndromes [9]. In addition, the risk of a pancreatic carcinoma is increased by a factor of 16 in chronic pancreatitis [5]. Diagnosis is made based on clinical, morphological, and functional parameters of the disease. Since these three points correlate only insufficiently with the clinical symptoms, which primarily consist of non-specific abdominal pain, clinical as well as morphological and functional diagnostic methods are to be used in a complementary manner.

\section{Diagnosis of the disease \\ $\nabla$}

The guidelines recommend transabdominal sonographic examination of the pancreas as the primary imaging method following careful recording of the anamnesis and clinical examination. In the case of an unclear finding in sonography which should typically show an inhomogeneous organ and changes to the pancreatic duct, endosonographic (EUS) clarification can be performed as a further method and can be followed by histological or cytological diagnosis with EUS-supported fine-needle puncture. Computed tomography (CT) and magnetic resonance imaging (MRI) with magnetic resonance cholangiopancreatography (MRCP) are defined as supplementary diagnostic methods in the case of unclear pancreatic changes on ultrasound and endosonography. These recommendations are specified with evidence level IIA and recommendation level B. According to the literature, endosonography achieves similar results to endoscopic retrograde pancreatography (ERP) with respect to disease diagnosis but does not involve the complications and side effects of ERP [10-13]. Therefore, the relatively stressful and invasive ER(C)P method is no longer viewed as the gold standard in the current guideline. MRI with MRCP has also shown high sensitivities in prospective studies in the diagnosis of a malignancy and with a sensitivity of $84 \%$ and a specificity of $94 \%$ even appears superior to ERCP [14]. Among diagnostic methods, EUS is the leading method with regard to sensitivity and specificity. However, there are only a limited number of studies and no adequate meta-analyses ( $\bullet$ Table 1 ). Unfortunately, there are no large prospective randomized studies comparing computed tomography with EUS and ultrasound in chronic pancreatitis. There are only comparative prospective studies for ERCP with EUS and MRCP with EUS $[15,16]$ as well as ultrasound with ERCP [17].

With respect to the possible administration of secretin for better visualization of the pancreatic ducts in MRCP, there are no definitive statements and recommendations in the guidelines due to a lack of comparative prospective literature in adults [18-21]. The administration of secretin is only recommended in the diagnosis of pediatric patients to increase the diagnostic relevance of MRCP on the basis of two publications $[21,22]$.

Based on the currently available studies and socioeconomic aspects, sonography should therefore be performed first in the case of suspicion of chronic pancreatitis. In the case of a normal imaging finding, EUS possibly with puncture for histology or with cytology can then be additionally performed [23-25]. CT and especially MRI with MRCP are important for further diagnostics and for possible treatment planning

Table 1 Sensitivity and specificity of imaging methods for diagnosing chronic pancreatitis according to the current literature.

\begin{tabular}{lllll}
$\begin{array}{l}\text { exami- } \\
\text { nation }\end{array}$ & sensitivity & specificity & evidence & references \\
\hline CT & $n / a$ & $n / a$ & $2 b$ & {$[15]$} \\
\hline ERCP & $70-80 \%$ & $80-100 \%$ & $2 a$ & {$[14,15,47-50]$} \\
\hline MRCP & $88 \%$ & $98 \%$ & $2 b$ & {$[16,28]$} \\
\hline US & $60-81 \%$ & $70-97 \%$ & $2 a$ & {$[14,26,51]$} \\
\hline EUS & $80-100 \%$ & $80-100 \%$ & $2 a$ & {$[23,24,48,52,53]$} \\
\hline
\end{tabular}


in terms of surgical planning or the differential diagnosis of tumors $[15,26]$.

\section{Imaging classification}

$\nabla$

Modifications of the Cambridge classification, which was primarily created for ERC, CT, and ultrasound, should be used to classify chronic pancreatitis with imaging methods ( $\triangle$ Table 2) [27]. In the case of ERC, a classification of Cambridge 0 indicates absolutely no pathological change of the pancreatic duct, Cambridge I indicates less than 3 pathological side branches with a normal main duct, Cambridge II indicates more than 3 pathological side branches with a normal main duct, and Cambridge III indicates more than 3 pathological side branches with a pathological main duct. Cambridge IV additionally includes cystic changes and duct stones and strictures. As mentioned above, the original Cambridge classification was limited to duct visualization via ERP with an expansion to include CT and ultrasound.
Therefore, adaptations and standardizations of the nomenclature for sonography, CT and primarily MRCP are being undertaken and will be important for future multimodal clinical studies [12, 18, $28-30]$. In the radiological adaptation of the Cambridge classification ( $\bullet$ Fig. $1-3$ ) for CT and MRI, the modification of Cambridge 0 entails absolutely no changes. Changes cannot be defined in Cambridge 1 with current CT and MRI techniques. In the CT/MRCP modification, Cambridge 2 means 2 or more of the following changes ( $\bullet$ Fig. 1): Pancreatic duct between $2 \mathrm{~mm}$ and $4 \mathrm{~mm}$ in the body of the pancreas, discrete enlargement of the pancreas, heterogeneous parenchymal structures, cystic changes $<10 \mathrm{~mm}$, duct irregularities, pathological side ducts. In the case of Cambridge 3 ( $\bullet$ Fig. 2 ), all of the changes mentioned for II must be present with a pathological main duct, while in Cambridge 4 ( $\bullet$ Fig. 3 ) cystic structures $>10 \mathrm{~mm}$ with parenchymal calcifications ( $\bullet$ Fig.4), interductal defects, duct obstructions, and severe duct irregularities must additionally be present. In contrast to the ERP-based Cambridge classification, changes in the pancreatic parenchyma are

Table 2 Summary of the Cambridge classification with modification for CT and MRCP.

\begin{tabular}{|c|c|c|}
\hline Cambridge & ERCP & $\mathrm{CT} / \mathrm{MRCP}$ \\
\hline 0 & $\begin{array}{l}\text { no pathological changes with complete visualization of } \\
\text { the pancreatic duct }\end{array}$ & none \\
\hline 1 & $\begin{array}{l}\text { fewer than } 3 \text { pathological side branches, normal main } \\
\text { duct }\end{array}$ & cannot be delimited in CT/MRCP with current methods \\
\hline 2 & 3 or more pathological side branches, normal main duct & $\begin{array}{l}2 \text { or more of the following changes: } \\
\text { - pancreatic duct between } 2 \text { and } 4 \text { mm in the body of the pancreas } \\
\text { - slight enlargement of the pancreas } \\
\text { - heterogeneous parenchymal structure } \\
\text { - small cystic changes }(<10 \mathrm{~mm}) \\
\text { - duct irregularities } \\
\text { - } 3 \text { or more pathological side ducts }\end{array}$ \\
\hline 3 & $\begin{array}{l}3 \text { or more pathological side branches plus pathological } \\
\text { main duct }\end{array}$ & all changes specified in 2 plus pathological main duct (> $4 \mathrm{~mm}$ ) \\
\hline 4 & $\begin{array}{l}\text { as in } 3 \text { plus cysts, duct stones, strictures, involvement of } \\
\text { neighboring organs }\end{array}$ & $\begin{array}{l}\text { one of the changes specified in } 2 \text { and } 3 \text { plus one or more of the following: } \\
\text { - cystic structures }>10 \mathrm{~mm} \\
\text { - parenchymal calcifications intraductal filling defects (chalk stones) } \\
\text { - duct obstruction (strictures), severe duct irregularities }\end{array}$ \\
\hline
\end{tabular}
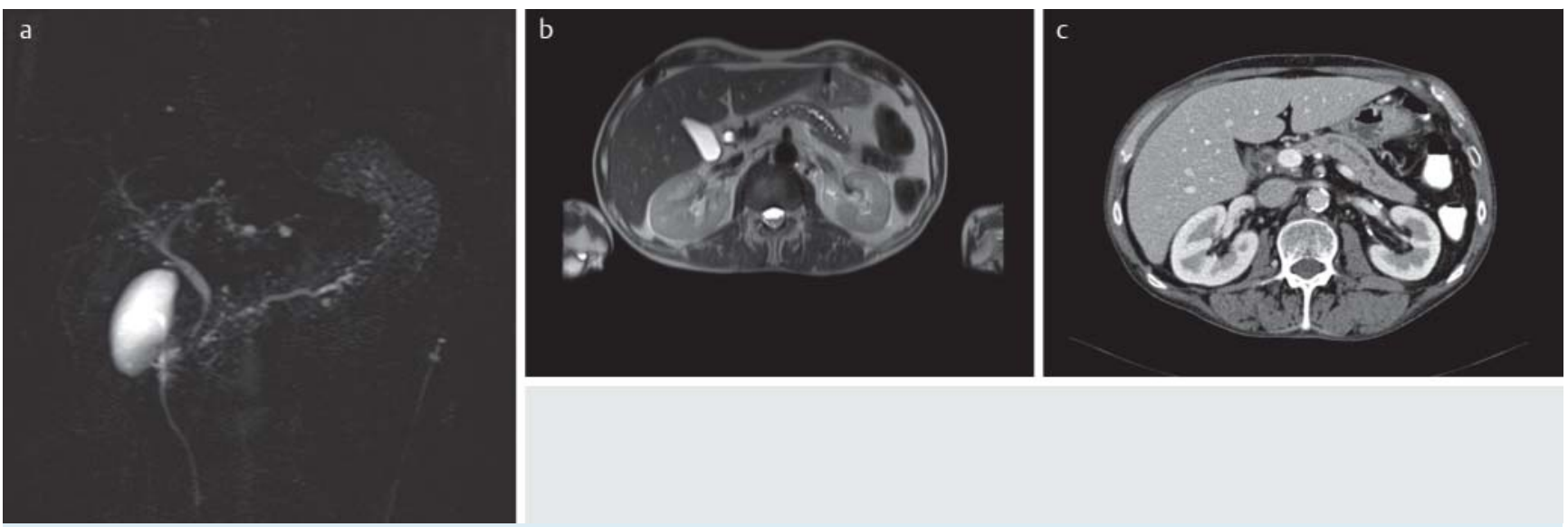

Fig. 1 56-year-old patient with chronic pancreatitis (Cambridge 2): a Coronary 3D-MIP-MRCP with discretely dilated pancreatic duct (to $3 \mathrm{~mm}$ ) with duct irregularities and small, cystic changes. b Corresponding axial T2 se- quence with irregularities of the pancreatic duct and cystic lesions of the pancreas. c Axial CT on corresponding slice plane in the portal venous phase with emphasis of the pancreatic duct without evidence of calcifications. 

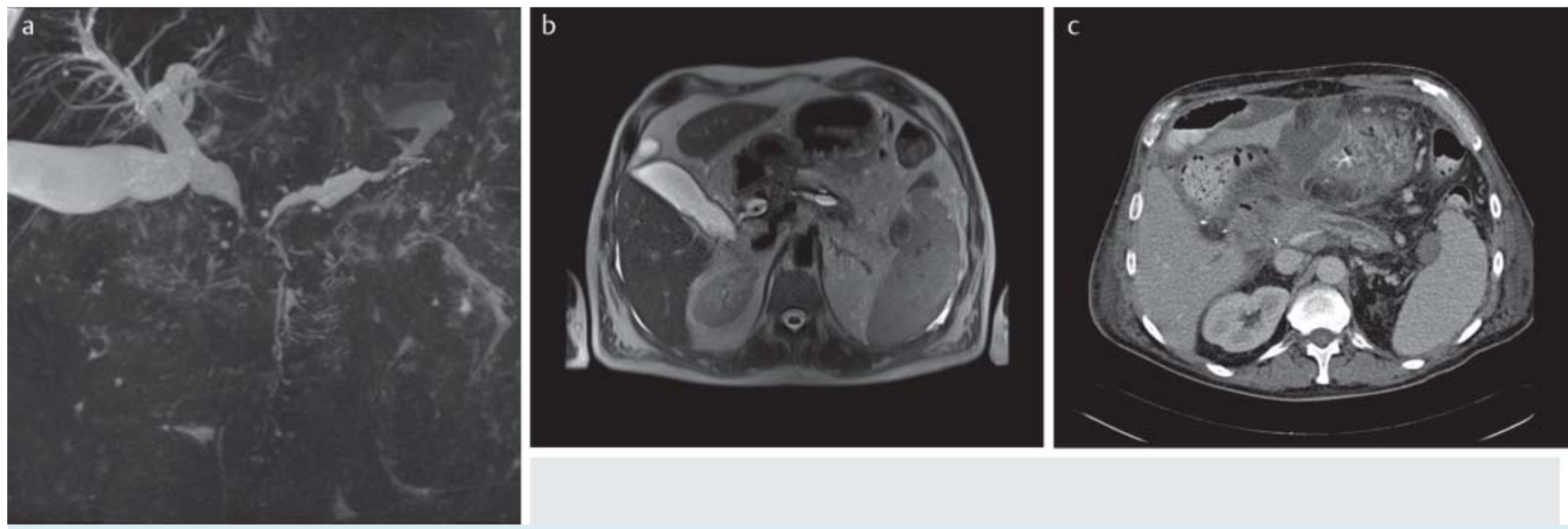

Fig. 2 63-year-old patient with chronic pancreatitis (Cambridge 3): a Coronary 3D-MIP-MRCP with greatly dilated pancreatic duct (>4 mm) with significant duct irregularities and cystic changes, pathological pancreatic side branches and intra- and extrahepatic cholestasis. $\mathbf{b}$ Corresponding axial
T2 sequence with significantly dilated pancreatic duct and cystic lesions of the pancreas. c Axial CT on corresponding slice plane in portal venous phase with dilated pancreatic duct and start of calcification in the head of the pancreas.
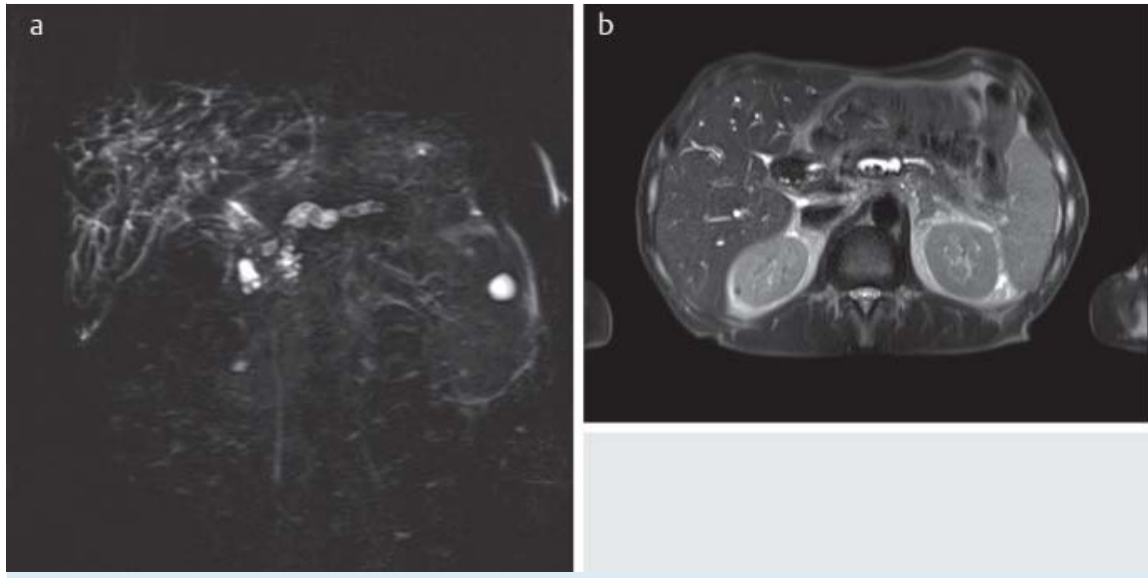

Fig. 3 58-year-old patient with chronic pancreatitis (Cambridge 4): a Coronary 3D-MIP-MRCP with massively dilated pancreatic duct $(>4 \mathrm{~mm})$ with strictures and evidence of intraductal filling defects. $\mathbf{b}$ Corresponding axial
T2 sequence with dilation of the pancreatic duct, duct stricture, and intraductal filling defects. c Axial CT on corresponding slice plane in portal venous phase with dilated pancreatic ducts and intraductal chalk stones. also taken into consideration in the imaging methods. In principle, this classification should be primarily used for study classification since it provides a uniform classification even for different imaging methods.

\section{Imaging of typical complications of chronic pancreatitis \\ $\nabla$}

In the case of necrosis, contrast-enhanced ultrasound examination (CEUS) is put on par with contrast-enhanced CT even though an evaluation of severity as in CT is not possible [31]. Moreover, this statement is based on a single publication and has not yet been confirmed by further studies [32]. In the clinical routine contrast-enhanced CT continues to be the method of choice due to its high availability and objectivity especially since CEUS currently still requires a high degree of specialization on the part of the examiner. Contrast-enhanced MRI can also be used with the same sensitivity and specificity. However, this still plays a secondary role in practice $[32,33]$.

In the case of cysts ( $\bullet$ Fig. 5), transabdominal ultrasound is initially viewed as sufficient. EUS and MRI with MRCP are specified as additional methods for differentiation with a higher transfer rate between pancreatic lesions. However, sonography should typically be sufficient [34].

In the case of vascular changes, pseudoaneurysms in particular are a typical complication. Basic diagnosis via sonography with additional color Doppler is typically sufficient in most cases. For interventional and surgical planning, CT angiography or MR angiography should be performed. However, as in the case of sonography, there are also no adequate comparative studies here.

\section{Differential diagnosis in chronic pancreatitis $\nabla$}

When diagnosing pancreatic carcinomas in patients with chronic pancreatitis, regular percutaneous ultrasound pro- 


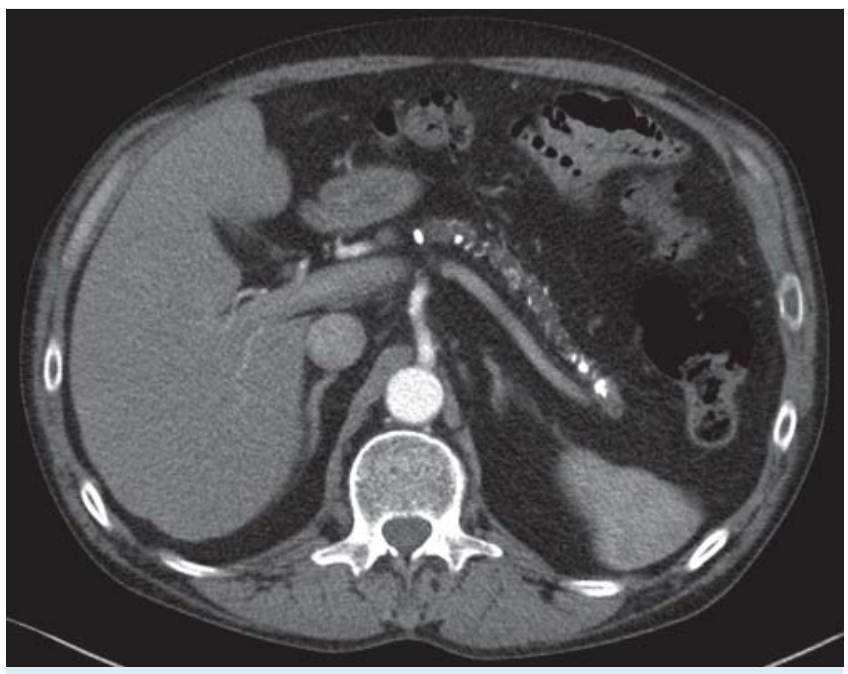

Fig. 4 48-year-old patient with chronic pancreatitis (Cambridge 4): Contrast-enhanced $\mathrm{CT}$ of the upper abdomen shows multiple calcifications in the atrophied pancreatic parenchyma. vides insufficient differentiation between carcinomas and inflammatory changes. EUS with fine-needle puncture has a sensitivity of over $85 \%[35,36]$. For MRI with MRCP current studies specify sensitivities of approximately $84 \%$ with a specificity of $97 \%$, while a sensitivity of $93 \%$ and a specificity of $75 \%$ were calculated for the differentiation between focal pancreatic masses in chronic pancreatitis and pancreatic carcinomas [37]. Both necrotic changes and pancreatic carcinomas have hypoperfused areas. Since EUSbased fine-needle puncture has a relatively high rate of false-negative findings, its use for ruling out surgical treatment also seems limited [38]. Histological or cytological fine-needle puncture can be helpful for the differentiation between autoimmune pancreatitis and other pancreatic diseases since up to $40 \%$ of cases of autoimmune pancreatitis present with focal lesions [39]. In principle, there is virtually no diagnostic value in performing ERP as a primary diagnostic method. Four criteria with a high sensitivity and specificity were defined only for autoimmune pancreatitis. Long stenoses $>1 / 3$ of the pancreatic length, a lack of dilation of the downstream pancreatic duct, dilation of the side branches and multifocal strictures in the course of the pancreatic duct are described as changes indicative of autoimmune pancreatitis [34]. ERP is therefore still required for diagnosing autoimmune pancreatitis in the Japanese guidelines. ERP is explicitly not specified as the primary diagnostic method in the German S3 guideline. Instead, EUS and/or MRI with MRCP is recommended. ERP should only be performed in individual cases of unclear EUS or MRCP findings.

\section{Treatment of typical complications}

$\nabla$

Pancreatic pseudocysts are the most common complication of both acute and chronic pancreatitis with the prevalence in chronic pancreatitis being $20-40 \%$ [40]. Pancreatic pseudocysts are most common in patients with alcoholbased chronic pancreatitis [2]. Pancreatic pseudocysts spontaneously regress 6 weeks after formation in up to $40 \%$ of patients. If pseudocysts persist for more than 12

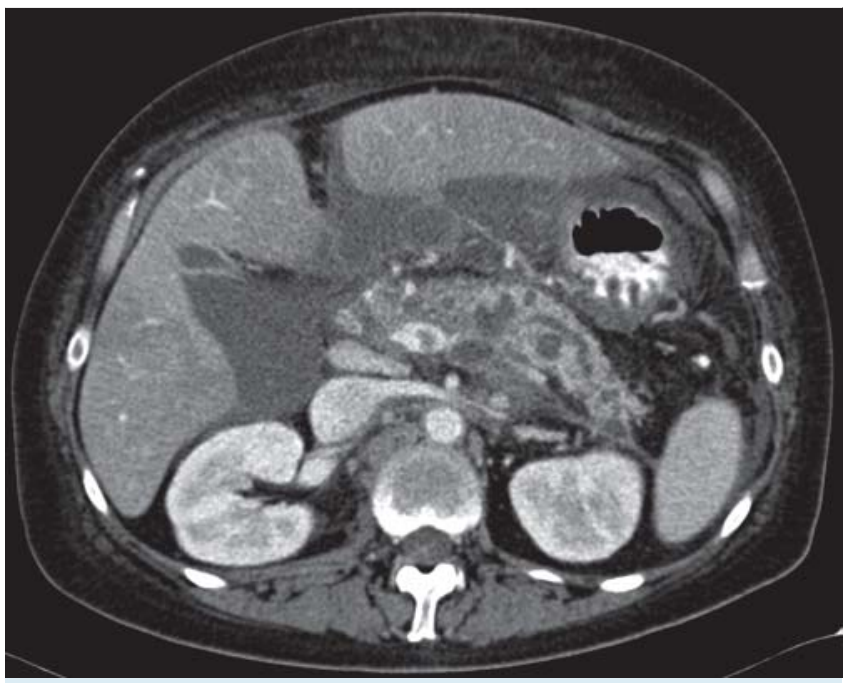

Fig. 5 52-year-old patient with chronic pancreatitis (Cambridge 4): CT of the upper abdomen shows cystic changes in the pancreatic parenchyma with a dilated and irregular pancreatic duct.

weeks, spontaneous remission is very improbable with additional complications occurring in up to $60 \%$ of cases [41]. The timing and the performing of possible therapeutic interventions in the case of pancreatic pseudocysts were partially controversial in the guideline discussion. According to the published guidelines, pseudocysts with a total size of over $5 \mathrm{~cm}$ and a capsule with a thickness of more than $5 \mathrm{~mm}$ were associated with complications. Treatment can be in the form of surgery in terms of fenestration or percutaneous and endoscopic drainage. The data regarding intervention in the case of pseudocysts is very limited. There are no suitable prospective studies. Placement of a stent in the bile duct can be sufficient in the case of cholestasis caused by a pseudocyst. In the case of compression of larger vessels or gastric outlet stenoses, the pancreatic pseudocyst should be drained. However, an endoscopic endoluminal drainage procedure that seems to have fewer complications than a surgical approach should be given preference $[34,40]$. In principle, percutaneous radiological procedures are possible but are associated with a high risk of external fistula formation so that this method should not be performed if endoscopic drainage is possible. Particularly in the case of infected cysts, drains placed under radiology guidance have worse results than endoscopically placed drains. However, both minimally invasive procedures are better than the surgical approach [40].

\section{Vascular complications}

$\nabla$

In particular, vascular pseudoaneurysms in chronic pancreatitis must be mentioned here. These should be treated due to a risk of bleeding although there are no evidence-based prospective studies. Bleeding pseudoaneurysms should be treated due to the low morbidity of the radiological-interventional method compared to surgery with angiographic embolization. According to the literature, the success rate of angiography is approximately $66 \%$ [42]. 


\section{Follow-up}

Examinations and imaging methods in intervals between 6 and 12 months after diagnosis are recommended for clinical follow-up to detect complications early. However, there are insufficient studies to support this time interval. In addition to clinical and laboratory examinations, follow-up primarily with transabdominal ultrasound examinations is recommended and with a sensitivity of approximately $60-81 \%$ is largely in the range of the sensitivity of CT or MRI examinations ( $\bullet$ Table 1 ). The only problem with ultrasound examination is poor specificity of approximately $35 \%$ so that the examination should be supplemented by EUS, ERCP, CT, or MRI in the case of unclear findings [43]. In the case of suspicion of a complication or the formation of a pancreatic carcinoma, the corresponding imaging (CT or MRI/MRCP) must be performed in the further course. None of the described methods has sufficient reliability to definitively rule out an operable malignancy in the case of chronic pancreatitis. According to the current literature, endosonography seems to be superior particularly due to the possibility to take biopsies. However, MRI with MRCP can be assigned a higher diagnostic value $[14,36]$. Tumor markers are not very helpful with respect to pancreatic carcinomas in patients with chronic pancreatitis. The diagnostic sensitivity and specificity are not sufficient. The extent to which MRI together with diffusion-weighted sequences and dynamic MRI examinations can provide additional differential diagnostic help must be further clarified. Based on the current literature, it seems rather improbable that MRI with diffusion-weighted sequences will result in a relevant improvement in differential diagnosis [44-46].

\section{Summary}

According to the first evidence-based German S3 guidelines regarding the diagnosis and treatment of chronic pancreatitis, transabdominal sonography is the basic examination of choice for initial diagnosis as well as in the further course for early clarification of possible complications. MRI with MRCP has a very high diagnostic value both for classification for studies and for early diagnosis and differential diagnosis of possible pancreatic carcinomas that frequently occur in patients with chronic pancreatitis. The Cambridge classification should be used in studies since it provides comparable classifications and results via modifications for the most important imaging methods. Transcutaneous methods should only be used on a limited basis in the treatment of complications, such as pancreatic pseudocysts, since fistula formation is a common complication. Angiographic embolization of vascular aneurysms in chronic pancreatitis is the method of choice for acute bleeding or for prophylaxis.

\section{References}

1 Dufour MC, Adamson MD. The epidemiology of alcohol-induced pancreatitis. Pancreas 2003; 27: 286-290

2 Ammann RW, Akovbiantz A, Largiader F et al. Course and outcome of chronic pancreatitis. Longitudinal study of a mixed medical-surgical series of 245 patients. Gastroenterology 1984; 86: 820-828

3 Miyake $\mathrm{H}$, Harada $\mathrm{H}$, Kunichika $\mathrm{K}$ et al. Clinical course and prognosis of chronic pancreatitis. Pancreas 1987; 2: 378-385
4 Lankisch PG, Lohr-Happe A, Otto J et al. Natural course in chronic pancreatitis. Pain, exocrine and endocrine pancreatic insufficiency and prognosis of the disease. Digestion 1993; 54: 148-155

5 Lowenfels AB, Maisonneuve P, Cavallini $G$ et al. Prognosis of chronic pancreatitis: an international multicenter study. International Pancreatitis Study Group. The American journal of gastroenterology 1994; 89: 1467 - 1471

6 Levy P, Mathurin P, Roqueplo A et al. A multidimensional case-control study of dietary, alcohol, and tobacco habits in alcoholic men with chronic pancreatitis. Pancreas 1995; 10: 231 - 238

7 Yan MX, Li YQ. Gall stones and chronic pancreatitis: the black box in between. Postgraduate medical journal 2006; 82: 254-258

8 Burtin P, Person B, Charneau J et al. Pancreas divisum and pancreatitis: a coincidental association? Endoscopy 1991; 23: 55-58

9 DiMagno EP, Go VL, Summerskill WH. Relations between pancreatic enzyme ouputs and malabsorption in severe pancreatic insufficiency. The New England journal of medicine 1973; 288: 813-815

10 Catalano MF, Geenen JE. Diagnosis of chronic pancreatitis by endoscopic ultrasonography. Endoscopy 1998; 30 Suppl 1: A111 -A115

11 Catalano MF, Lahoti S, Geenen JE et al. Prospective evaluation of endoscopic ultrasonography, endoscopic retrograde pancreatography, and secretin test in the diagnosis of chronic pancreatitis. Gastrointestinal endoscopy $1998 ; 48: 11-17$

12 Catalano MF, Sahai A, Levy $M$ et al. EUS-based criteria for the diagnosis of chronic pancreatitis: the Rosemont classification. Gastrointestinal endoscopy 2009; 69: 1251 - 1261

13 Chong AK, Hawes RH, Hoffman BJ et al. Diagnostic performance of EUS for chronic pancreatitis: a comparison with histopathology. Gastrointestinal endoscopy 2007; 65: 808 -814

14 Adamek HE, Albert J, Breer $H$ et al. Pancreatic cancer detection with magnetic resonance cholangiopancreatography and endoscopic retrograde cholangiopancreatography: a prospective controlled study. Lancet 2000; 356: 190 - 193

15 Buscail L, Escourrou J, Moreau J et al. Endoscopic ultrasonography in chronic pancreatitis: a comparative prospective study with conventional ultrasonography, computed tomography, and ERCP. Pancreas 1995; 10: $251-257$

16 Wiersema MJ, Hawes RH, Lehman GA et al. Prospective evaluation of endoscopic ultrasonography and endoscopic retrograde cholangiopancreatography in patients with chronic abdominal pain of suspected pancreatic origin. Endoscopy 1993; 25: 555 - 564

17 Gebel M, Stiehl M, Freise J. Value of sonographic imaging of the pancreatic duct for the diagnosis of chronic pancreatitis and pancreatic cancer compared to ERCP. Ultraschall in Med 1985; 6: 127-130

18 Sai JK, Suyama M, Kubokawa Y et al. Diagnosis of mild chronic pancreatitis (Cambridge classification): comparative study using secretin injection-magnetic resonance cholangiopancreatography and endoscopic retrograde pancreatography. World journal of gastroenterology: WJG 2008; 14: $1218-1221$

19 Bali MA, Golstein P, Deviere J et al. Evaluation of somatostatin inhibitory effect on pancreatic exocrine function using secretin-enhanced dynamic magnetic resonance cholangiopancreatography: a crossover randomized, double blind, placebo-controlled study. Pancreas 2006; 32: $346-350$

20 Donati F, Boraschi P, Gigoni R et al. Secretin-stimulated MR cholangiopancreatography in the evaluation of asymptomatic patients with non-specific pancreatic hyperenzymemia. European journal of radiology 2010; 75: e38-e44

21 Manfredi R, Lucidi V, Gui B et al. Idiopathic chronic pancreatitis in children: MR cholangiopancreatography after secretin administration. Radiology 2002; 224: 675-682

22 Darge K, Anupindi S. Pancreatitis and the role of US, MRCP and ERCP. Pediatric radiology 2009; 39 (Suppl 2): S153 - S157

23 Kahl S, Glasbrenner B, Leodolter A et al. EUS in the diagnosis of early chronic pancreatitis: a prospective follow-up study. Gastrointestinal endoscopy 2002; 55: 507 - 511

$24 \mathrm{Kahl}$ S, Glasbrenner B, Zimmermann S et al. Endoscopic ultrasound in pancreatic diseases. Digestive diseases 2002; 20: 120-126

25 Gebel M, Stiehl M, Freise J. Value of sonographic imaging of the pancreatic duct for the diagnosis of chronic pancreatitis and pancreatic cancer compared to ERCP. Ultraschall in der Medizin 1985; 6: 127-130

26 Glasbrenner B, Kahl S, Malfertheiner P. Modern diagnostics of chronic pancreatitis. European journal of gastroenterology \& hepatology 2002; 14: 935 - 941 
27 Sarner M, Cotton PB. Classification of pancreatitis. Gut 1984; 25: 756 759

28 Tamura R, Ishibashi T, Takahashi S. Chronic pancreatitis: MRCP versus ERCP for quantitative caliber measurement and qualitative evaluation. Radiology 2006; 238: 920-928

29 Testoni PA, Mariani A, Curioni S et al. MRCP-secretin test-guided management of idiopathic recurrent pancreatitis: long-term outcomes. Gastrointestinal endoscopy 2008; 67: 1028-1034

30 Nattermann C, Goldschmidt AJ, Dancygier H. Endosonography in chronic pancreatitis. A comparative study of endoscopic retrograde pancreatography and endoscopic sonography. Ultraschall in der Medizin 1992; 13: $263-270$

31 Balthazar EJ, Robinson DL, Megibow AJ et al. Acute pancreatitis: value of CT in establishing prognosis. Radiology 1990; 174: $331-336$

32 Rickes S, Uhle C, Kahl S et al. Echo enhanced ultrasound: a new valid initial imaging approach for severe acute pancreatitis. Gut 2006; 55 : $74-78$

33 Arvanitakis $M$, Delhaye $M$, De Maertelaere $V$ et al. Computed tomography and magnetic resonance imaging in the assessment of acute pancreatitis. Gastroenterology 2004; 126: 715-723

34 Lerch MM, Stier A, Wahnschaffe $U$ et al. Pancreatic pseudocysts: observation, endoscopic drainage, or resection? Deutsches Arzteblatt international 2009; 106: 614-621

35 Fritscher-Ravens A, Brand L, Knofel WT et al. Comparison of endoscopic ultrasound-guided fine needle aspiration for focal pancreatic lesions in patients with normal parenchyma and chronic pancreatitis. The American journal of gastroenterology 2002; 97: 2768-2775

36 Will $U$, Mueller A, Topalidis $T$ et al. Value of endoscopic ultrasonography-guided fine needle aspiration (FNA) in the diagnosis of neoplastic tumor(-like) pancreatic lesions in daily clinical practice. Ultraschall in der Medizin 2010; 31: 169-174

37 Kim JK, Altun E, Elias JJr et al. Focal pancreatic mass: distinction of pancreatic cancer from chronic pancreatitis using gadolinium-enhanced 3D-gradient-echo MRI. Journal of magnetic resonance imaging: JMRI 2007; 26: 313-322

38 Ardengh JC, Paulo GA, Nakao FS et al. Endoscopic ultrasound guided fine-needle aspiration core biopsy: comparison between an automatic biopsy device and two conventional needle systems. Acta gastroenterologica Latinoamericana 2008; 38: 105-115

39 Chari ST, Smyrk TC, Levy MJ et al. Diagnosis of autoimmune pancreatitis: the Mayo Clinic experience. Clinical gastroenterology and hepatology: the official clinical practice journal of the American Gastroenterological Association 2006; 4: 1010 - 1016; quiz 1934

40 Barthet M, Bugallo M, Moreira LS et al. Management of cysts and pseudocysts complicating chronic pancreatitis. A retrospective study of 143 patients. Gastroenterologie clinique et biologique 1993; 17: 270-276
41 Bradley EL, Clements JL Jr, Gonzalez AC. The natural history of pancreatic pseudocysts: a unified concept of management. American journal of surgery 1979; $137: 135-141$

42 Udd M, Leppaniemi AK, Bidel S et al. Treatment of bleeding pseudoaneurysms in patients with chronic pancreatitis. World journal of surgery 2007; 31: $504-510$

43 Rosch T, Schusdziarra V, Born P et al. Modern imaging methods versus clinical assessment in the evaluation of hospital in-patients with suspected pancreatic disease. The American journal of gastroenterology 2000; 95: 2261 - 2270

44 Wiggermann P, Grutzmann R, Weissenbock A et al. Apparent diffusion coefficient measurements of the pancreas, pancreas carcinoma, and mass-forming focal pancreatitis. Acta radiologica 2012; 53: 135-139

45 Sandrasegaran $K$, Nutakki $K$, Tahir B et al. Use of diffusion-weighted MRI to differentiate chronic pancreatitis from pancreatic cancer. Am J Roentgenol American journal of roentgenology 2013; 201: 10021008

46 Ichikawa T, Erturk SM, Motosugi $U$ et al. High-b value diffusion-weighted MRI for detecting pancreatic adenocarcinoma: preliminary results. Am J Roentgenol American journal of roentgenology 2007; 188: 409414

47 Chowdhury R, Bhutani MS, Mishra G et al. Comparative analysis of direct pancreatic function testing versus morphological assessment by endoscopic ultrasonography for the evaluation of chronic unexplained abdominal pain of presumed pancreatic origin. Pancreas 2005; 31: $63-68$

48 Pungpapong S, Wallace MB, Woodward TA et al. Accuracy of endoscopic ultrasonography and magnetic resonance cholangiopancreatography for the diagnosis of chronic pancreatitis: a prospective comparison study. Journal of clinical gastroenterology 2007; 41: 88-93

49 Stevens T, Conwell DL, Zuccaro G Jr et al. A prospective crossover study comparing secretin-stimulated endoscopic and Dreiling tube pancreatic function testing in patients evaluated for chronic pancreatitis. Gastrointestinal endoscopy 2008; 67: 458-466

50 Stevens T, Conwell DL, Zuccaro G Jr et al. Comparison of endoscopic ultrasound and endoscopic retrograde pancreatography for the prediction of pancreatic exocrine insufficiency. Digestive diseases and sciences 2008; 53: 1146-1151

51 Stevens T, Zuccaro GJr, Dumot JA et al. Prospective comparison of radial and linear endoscopic ultrasound for diagnosis of chronic pancreatitis. Endoscopy 2009; 41: 836-841

52 Hollerbach S, Ruser J, Ochs A et al. Current status of abdominal pancreatic ultrasound. A retrospective analysis of 585 pancreatic ultrasound examinations. Medizinische Klinik 1994; 89: 7-13

53 Lohr M, Kloppel G. Pathology of the pancreas in chronic type 1 diabetes mellitus: B-cell content, exocrine atrophy and angiopathy. Verhandlungen der Deutschen Gesellschaft fur Pathologie 1987; 71: 114-119 